\title{
GPS-BASED MONITORING OF CRUSTAL DEFORMATION IN GARHWAL-KUMAUN HIMALAYA
}

\author{
Y. Sharma ${ }^{1, *}$, S. Pasari ${ }^{1}$, O. Dikshit ${ }^{2}$, K.E. Ching ${ }^{3}$ \\ ${ }^{1}$ Birla Institute of Technology \& Science, Pilani - (yogenmaths2738, 86.sumanta)@gmail.com \\ ${ }^{2}$ Indian Institute of Technology Kanpur - onkar@,iitk.ac.in \\ ${ }^{3}$ National Cheng Kung University, Tainan, Taiwan - kuenmiao@yahoo.com.tw
}

Commission V, SS: Disaster Monitoring, Damage Assessment and Risk Reduction

KEYWORDS: Earthquakes, GPS, GAMIT-GLOBK, Garhwal-Kumaun Himalaya, Slip rate

\begin{abstract}
:
The Himalayan region has experienced a number of large magnitude earthquakes in the past. Seismicity is mainly due to tectonic activity along the thrust faults that trend parallel to the Himalayan mountain belt. In order to study the ongoing tectonic process, we report Global Positioning System (GPS) measurements of crustal deformation in the Garhwal-Kumaun Himalaya through two continuous and 21 campaign stations. We collect GPS data since 2013 and analyze with the GAMIT/GLOBK suite of postprocessing software. Our estimated surface velocities in ITRF2008, India-fixed, and Eurasia-fixed reference frame lie in the range of $42-52 \mathrm{~mm} / \mathrm{yr}, 1-6 \mathrm{~mm} / \mathrm{yr}$, and $31-37 \mathrm{~mm} / \mathrm{yr}$, respectively. We observe insignificant slip rate $(\sim 1 \mathrm{~mm} / \mathrm{yr})$ of HFT that indicates its locking behavior. The slip rates of MBT and MCT, however, are consistent with the seismic activity of the study region.
\end{abstract}

\section{INTRODUCTION}

The Indian plate seated at the northwestern end of the IndoAustralian plate has been continuously colliding with the Eurasian plate since 50 Ma. The Himalayan syntaxis located just above this plate boundary forms an arc that extends $\sim 2400 \mathrm{~km}$ across the continent, starting from Kashmir Himalaya to Northeast India. This persistent collision breaks the Himalayan subcontinent into three active thrust faults, namely the Main Central Thrust (MCT), Main Boundary Thrust (MBT), and the Himalayan Frontal Thrust (HFT). It is believed that these three major faults meet into another thrust fault beneath the Himalaya, known as the Main Himalayan Thrust (MHT). This thrust system hosts many moderate to great hazardous earthquakes viz. 1905 Kangra earthquake (Mw 7.8), 1934 Bihar-Nepal earthquake (Mw 8.2), 1950 Assam earthquake (Mw 8.4), 2005 Kashmir earthquake (Mw 7.6), and 2015 Gorkha earthquake ( $\mathrm{Mw}$ 7.8). The occurrence of these disastrous earthquakes is a testimony to the ongoing tectonic process along the Himalayan arc. To study this tectonic activity many of geologic and geodetic studies have been undertaken. These studies suggest that the Indian plate is converging towards the Eurasian plate at a rate of $\sim 50 \mathrm{~mm} / \mathrm{yr}$. However, $50 \%$ of this convergence rate is accommodated in the Himalayan arc itself (England and Molnar, 1997; Holt et al., 2000; Wang et al., 2001).

\footnotetext{
${ }^{1}$ Corresponding author
}

The GPS measurements across the Himalaya in Nepal suggest a shortening rate of $\sim 20 \mathrm{~mm} / \mathrm{yr}$ (Bilham et al., 1997; Jouanne et al., 1999, 2004; Larson et al., 1999; Bettinelli et al., 2006). These GPS measured convergence rates are comparable with the long-term geological convergence rates. The HFT is the southernmost, youngest member of the Himalayan fold and thrust belt. A shortening rate of $21 \pm 1.5 \mathrm{~mm} / \mathrm{yr}$ along the HFT in the Nepal Himalaya inferred from fluvial terraces (Lave and Avouac, 2000). In further North of the HFT near MCT, the shortening rate estimated in the range of 7-19 $\mathrm{mm} / \mathrm{yr}$ (Schelling et al., 1991). In the NW Himalaya across the Kangra region, $14 \pm 2$ $\mathrm{mm} / \mathrm{yr}$ shortening rate was estimated from balanced cross section (Powers et al., 1998) and slip deficit rate of $14 \pm 1$ $\mathrm{mm} / \mathrm{yr}$ on the HFT deduced from GPS measurements (Banerjee and Burgmann, 2002). In the Dehradun region of Garhwal Himalaya, the long-term shortening rate of $11 \pm 5$ $\mathrm{mm} / \mathrm{yr}$ across the HFT was estimated (Powers et al., 1998; Wesnousky et al., 1999). Convergence rate of $15 \mathrm{~mm} / \mathrm{yr}$ was inferred from GPS observations across the Kumaun Himalaya (Ponraj et al., 2010). Further, for the MHT, the slip rate was estimated to be $10 \mathrm{~mm} / \mathrm{yr}$ (Ponraj et al., 2011) and the slip deficit rate was estimated to be $18 \mathrm{~mm} / \mathrm{yr}$ (Gautam et al., 2017) from GPS measurements.

\section{GPS DATA ACQUISITION AND ANALYSIS}

Our study area is the Garhwal-Kumaun region in the Northwest Himalaya (Figure 1). In this region two GPS 
networks were established in 2013. The first network comprises two permanent stations THKD $\left(29: 1486^{\circ} \mathrm{N}\right.$; $\left.78: 8569^{\circ} \mathrm{E}\right)$ and $\mathrm{DHLC}\left(29: 6741^{\circ} \mathrm{N} ; 79: 7870^{\circ} \mathrm{E}\right)$ along with eight campaign sites (NYGN, GTGH, MNGL, NATL, RAGT, CHRA, JNVN, ALMR) lying arc normal to the Himalayan foothills. The other network comprises 13 campaign sites (I001, I002, I006, I007, I009, I010, I011, I013, I015, I016, I017, I018, I019) along the Himalayan arc. Each permanent station is constructed on a concrete pillar on top of which the GPS antenna is mounted. The GPS receiver, connecting cables, solar panels, an uninterrupted power supply (UPS) for the power back up, and internal batteries for an emergency are placed to complete the site establishment. All of the campaign sites are chosen on the Reinforced Cement Concrete (RCC) government/private building rooftops with a clear sky visibility. The major geological fault lines passing through this GPS network are HFT (near Kaladungi, in between NYGN and GTGH), MBT (near Bajoon, close to I001), and Almora thrust (in between JNVN and ALMR). We extend our study region using published results in further north up to MCT to analyze the crustal deformation of whole Garhwal-Kumaun Himalaya.

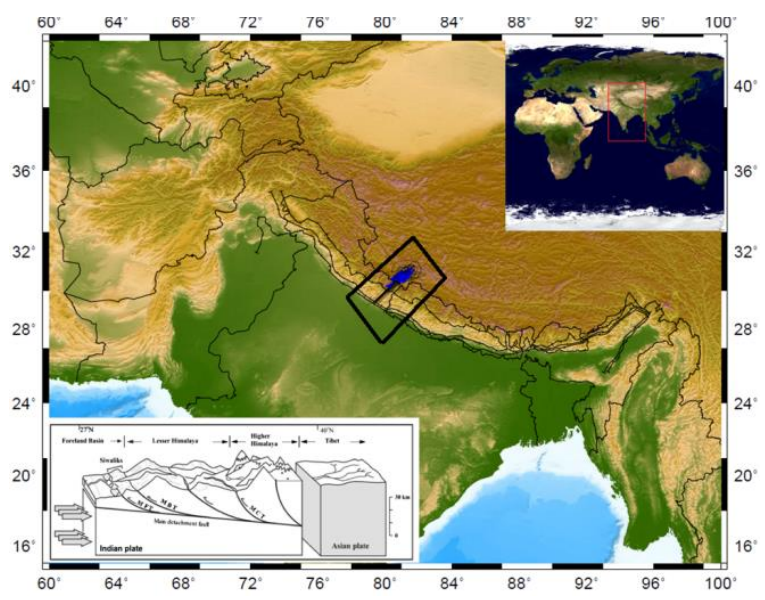

Figure 1. Study area in Garhwal-Kumaun Himalaya (Ponraj et al., 2010).

We use the GPS observation from two permanent and 21 campaign stations from 2013 to 2017. The GPS surveys are generally carried out annually for the permanent stations. All the campaign stations are occupied for 2-3 days twice or thrice in a year for data collection. The GPS data are process using the GAMIT/GLOBK suite of post-processing software (Herring et al., 2010) with International GPS Service (IGS) fiducial sites surrounding the Indian plate, namely, CHUM, COCO, DARW, DGAR, GUAO, HYDE, IISC, KIT3, LCK2, LHAZ, POL2, SHAO, SOLA, TEHN, URUM, and WUHN. In GAMIT, double difference carrier phase observations of GPS were used to estimate the station co-ordinates, receiver clock parameters, zenith delay, atmospheric delay, and orbital and Earth rotation parameters. To reduce errors in GPS-derived positions, solid Earth tides and ocean loading effect were taken into account by using the global tide model FES2004, which is a pure hydrodynamic tide model turned to fit tide gauges globally. The loosely constrained daily solutions (from GAMIT) of all regional stations are combined in GLOBK with the corresponding IGS daily solutions processed and archived at the Scripps Orbital and permanent Array Center (SOPAC). The repeated coordinates of GLOBK were plotted in a time-series plot using Generic Mapping Tool (GMT) and the GG-MATLAB (GAMIT-GLOBK MATLAB) toolbox for better visualization of the site movement.

\section{RESULTS}

Horizontal velocities estimated in International Terrestrial Reference Frame 2008 (ITRF2008) are observed to lie in the range of $42-52 \mathrm{~mm} / \mathrm{yr}$ with an uncertainty level of about $2 \mathrm{~mm}$. In addition, to analyze the deformational patterns in a regional scale, we re-calculate these velocities in India-fixed reference frame that lie in the range of 1-6 $\mathrm{mm} / \mathrm{yr}$ with an uncertainty level of $3 \mathrm{~mm}$. These velocities in the Eurasia-fixed reference frame lie in the range of $31-37 \mathrm{~mm} / \mathrm{yr}$ with an uncertainty level of $2 \mathrm{~mm}$.

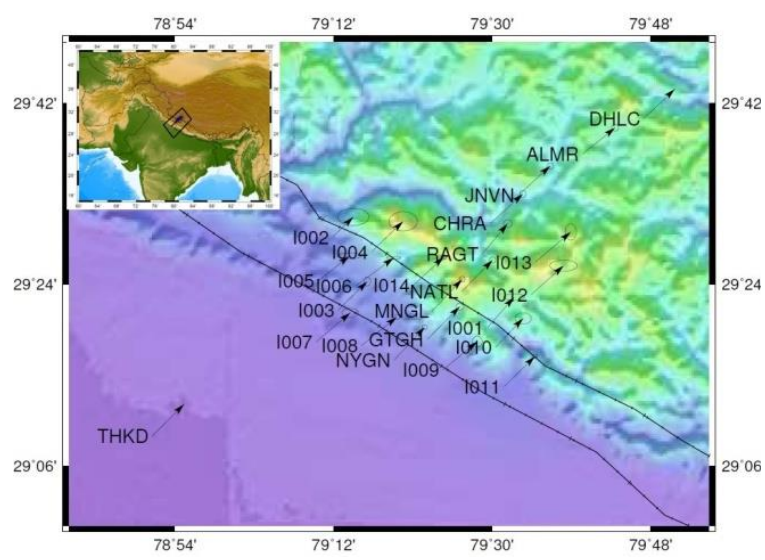

Figure 2. Surface velocities in ITRF08 of the GarhwalKumaun Himalaya with major fault lines.

Surface velocities of the two premanent stations estimated as $49 \mathrm{~mm} / \mathrm{yr}$ (THKD) and $47 \mathrm{~mm} / \mathrm{yr}$ (DHLC), whereas the velocities of all the campaign stations varies between 43 $\mathrm{mm} / \mathrm{yr}$ to $52 \mathrm{~mm} / \mathrm{yr}$ in ITRF2008 reference frame. The regional surface velocities are now used to estimate the underneath slip distribution and fault potential in the study region. In this regard, we have used a two-dimensional dislocation model inversion in an elastic, homogeneous and isotropic half-space (Okada, 1985, 1992). The initial fault parameters values for this dislocation model are provided 
from the available geological studies. In order to derive more detailed velocity field along Himalayan arc, many of the published velocity fields are combined so that they are consistent at the common reference frame (Banerjee et al., 2008; Ponraj et al., 2010; Kundu et al., 2014; Jade et al., 2017; Gautam et al., 2017).

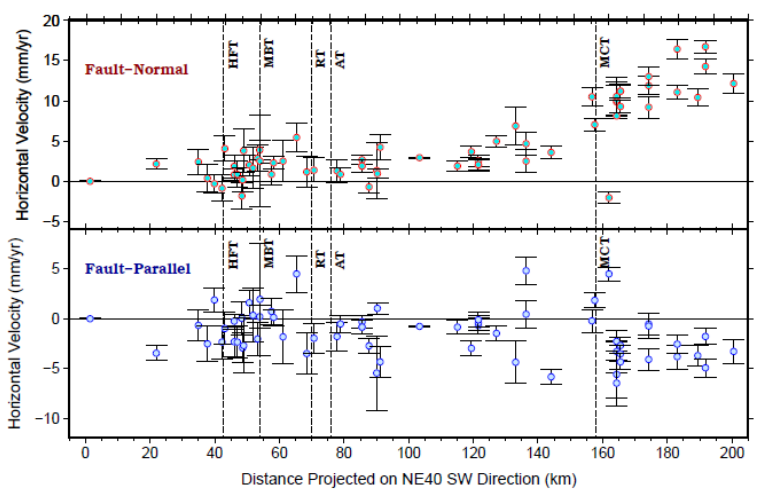

Figure 3. Fault-normal (red) along $\mathrm{N} 40^{\circ} \mathrm{E}$ and FaultParallel component (blue) across $\mathrm{N} 40^{\circ} \mathrm{E}$ after fixing THKD station along the $\mathrm{N} 290^{\circ} \mathrm{E}$ fault strike of the Himalayan arc.

We choose a $\mathrm{N} 40^{\circ} \mathrm{E}$ profile across $\mathrm{N} 290^{\circ} \mathrm{E}$ fault strike of the Himalayan arc. We fix the THKD station to see the relative movement of other sites. Fault-normal component along this profile varies from $-2 \mathrm{~mm} / \mathrm{yr}$ to $16 \mathrm{~mm} / \mathrm{yr}$ (Figure 3). This pattern of velocity gradient indicates dominant thrust faulting in the study region. Near the HFT fault-normal component does not show much variation in the relative movement with respect to fixed THKD station. We estimate the slip rate of HFT as $\sim 1 \mathrm{~mm} / \mathrm{yr}$ with the dip angle $\mathrm{N} 22^{\circ} \mathrm{E}$. Our estimation shows that the MBT is dipping at $\mathrm{N} 23^{\circ} \mathrm{E}$ with a slip rate of $\sim 10 \mathrm{~mm} / \mathrm{yr}$. In the further north of MBT near MCT, the fault normal component varies between $2 \mathrm{~mm} / \mathrm{yr}$ to $16 \mathrm{~mm} / \mathrm{yr}$ (Figure 3 ). The slip rate of MCT observe $\sim 6 \mathrm{~mm} / \mathrm{yr}$ with the dip angle
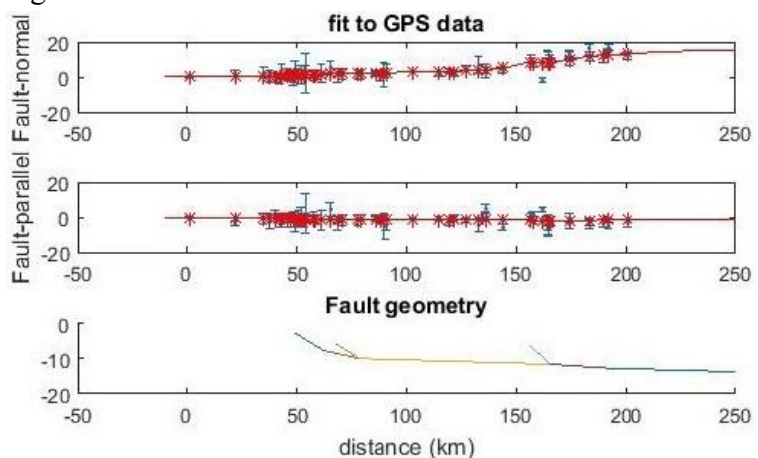

Figure 4. Fit to the Fault-Normal and Fault-Parallel component after fixing THKD station.
The fault-parallel component is fluctuates between -5 $\mathrm{mm} / \mathrm{yr}$ to $5 \mathrm{~mm} / \mathrm{yr}$. After fitting the GPS data, we observe that fault-parallel component shows a linear trend of velocity gradient (Figure 4).

\section{DISCUSSION}

The GPS measurements spanning five years (2013-2017) provide well-constrained present-day deformation rates in the Garhwal-Kumaun Himalaya. The slip rate of $\sim 1 \mathrm{~mm} / \mathrm{yr}$ for HFT show that it is locked and will eventually fail in future great earthquakes. This concept of locking of HFT is also consistent with some previous studies (Banerjee and Burgmann, 2002; Bettinelli et al., 2006; Ponraj et al., 2010; Jade et al., 2014; Dumka et al., 2014; Gautam et al., 2017). We found that in the further north of HFT, the MCT is seismically more active and release the strain energy over the time (Ponraj et al., 2011; Dumka et al., 2014, 2018; Jade et al., 2014). Finally, 2D modeling and strain accumulation studies with additional data sets will be carry out in the future study for improving our understanding of crustal deformation in the Garhwal-Kumaun Himalaya.

\section{REFERENCES}

Ader, T., Avouac, J.P., Liu-Zeng, J., Lyon-Caen, H., Bollinger, L., Galetzka, J., Genrich, J., Thomas, M., Chanard, K., Sapkota, S.N. and Rajaure, S., 2012. Convergence rate across the Nepal Himalaya and interseismic coupling on the Main Himalayan Thrust: Implications for seismic hazard. Journal of Geophysical Research: Solid Earth, 117(B4).

Banerjee, P. and Bürgmann, R., 2002. Convergence across the northwest Himalaya from GPS measurements. Geophysical Research Letters, 29(13), pp.30-1.

Banerjee, P., Bürgmann, R., Nagarajan, B. and Apel, E., 2008. Intraplate deformation of the Indian subcontinent. Geophysical Research Letters, 35(18).

Bettinelli, P., Avouac, J.P., Flouzat, M., Jouanne, F., Bollinger, L., Willis, P. and Chitrakar, G.R., 2006. Plate motion of India and interseismic strain in the Nepal Himalaya from GPS and DORIS measurements. Journal of Geodesy, 80(8-11), pp.567-589.

Bilham, R., Larson, K. and Freymueller, J., 1997. GPS measurements of present-day convergence across the Nepal Himalaya. Nature, 386(6620), p.61.

Dumka, R.K., Kotlia, B.S., Kumar, K. and Satyal, G.S., 2014. Quantification of crustal strain rate in Kumaun Himalaya (India) using GPS measurements of crustal deformation. Himalayan Geology, 35(2), pp.146-155. 
Dumka, R.K., Kotlia, B.S., Kothyari, G.C., Paikrey, J. and Dimri, S., 2018. Detection of high and moderate crustal strain zones in Uttarakhand Himalaya, India. Acta Geodaetica et Geophysica, 53(3), pp.503-521.

England, P. and Molnar, P., 1997. The field of crustal velocity in Asia calculated from Quaternary rates of slip on faults. Geophysical Journal International, 130(3), pp.551582.

Gautam, P.K., Gahalaut, V.K., Prajapati, S.K., Kumar, N., Yadav, R.K., Rana, N. and Dabral, C.P., 2017. Continuous GPS measurements of crustal deformation in GarhwalKumaun Himalaya. Quaternary International, 462, pp.124129.

Herring, T., King, R.W. and McClusky, S.C., 2010. GAMIT Reference Manual-GPS Analysis at MIT-Release 10.4, Dep. of Earth, Atm. and Planetary Sciences.

Holt, W.E., Chamot-Rooke, N., Le Pichon, X., Haines, A.J., Shen-Tu, B. and Ren, J., 2000. Velocity field in Asia inferred from Quaternary fault slip rates and Global Positioning System observations. Journal of Geophysical Research: Solid Earth, 105(B8), pp.19185-19209.

Jade, S., Mukul, M., Gaur, V.K., Kumar, K., Shrungeshwar, T.S., Satyal, G.S., Dumka, R.K., Jagannathan, S., Ananda, M.B., Kumar, P.D. and Banerjee, S., 2014. Contemporary deformation in the KashmirHimachal, Garhwal and Kumaon Himalaya: significant insights from 1995-2008 GPS time series. Journal of Geodesy, 88(6), pp.539-557.

Jade, S., Shrungeshwara, T.S., Kumar, K., Choudhury, P., Dumka, R.K. and Bhu, H., 2017. India plate angular velocity and contemporary deformation rates from continuous GPS measurements from 1996 to 2015. Scientific Reports, 7(1), p.11439.

Jouanne, F., Mugnier, J.L., Pandey, M.R., Gamond, J.F., Le Fort, P., Serrurier, L., Vigny, C. and Avouac, J.P., 1999. Oblique convergence in the Himalayas of western Nepal deduced from preliminary results of GPS measurements. Geophysical Research Letters, 26(13), pp.1933-1936.

Jouanne, F., Mugnier, J.L., Gamond, J.F., Le Fort, P., Pandey, M.R., Bollinger, L., Flouzat, M. and Avouac, J.P., 2004. Current shortening across the Himalayas of Nepal. Geophysical Journal International, 157(1), pp.1-14.

Kundu, B., Yadav, R.K., Bali, B.S., Chowdhury, S. and Gahalaut, V.K., 2014. Oblique convergence and slip partitioning in the NW Himalaya: implications from GPS measurements. Tectonics, 33(10), pp.2013-2024.

Larson, K.M., Bürgmann, R., Bilham, R. and Freymueller, J.T., 1999. Kinematics of the India-Eurasia collision zone from GPS measurements. Journal of Geophysical Research: Solid Earth, 104(B1), pp.1077-1093.

Lavé, J. and Avouac, J.P., 2000. Active folding of fluvial terraces across the Siwaliks Hills, Himalayas of central Nepal. Journal of Geophysical Research: Solid Earth, 105(B3), pp.5735-5770.

Okada, Y., 1985. Surface deformation due to shear and tensile faults in a half-space. Bulletin of the seismological society of America, 75(4), pp.1135-1154.

Okada, Y., 1992. Internal deformation due to shear and tensile faults in a half-space. Bulletin of the Seismological Society of America, 82(2), pp.1018-1040.

Ponraj, M., Miura, S., Reddy, C.D., Prajapati, S.K., Amirtharaj, S. and Mahajan, S.H., 2010. Estimation of strain distribution using GPS measurements in the Kumaun region of Lesser Himalaya. Journal of Asian Earth Sciences, 39(6), pp.658-667.

Ponraj, M., Miura, S., Reddy, C.D., Amirtharaj, S. and Mahajan, S.H., 2011. Slip distribution beneath the Central and Western Himalaya inferred from GPS observations. Geophysical Journal International, 185(2), pp.724-736.

Powers, P.M., Lillie, R.J. and Yeats, R.S., 1998. Structure and shortening of the Kangra and Dehra Dun reentrants, sub-Himalaya, India. Geological Society of America Bulletin, 110(8), pp.1010-1027.

Schelling, D. and Arita, K., 1991. Thrust tectonics, crustal shortening, and the structure of the far-eastern Nepal Himalaya. Tectonics, 10(5), pp.851-862.

Wang, Q., Zhang, P.Z., Freymueller, J.T., Bilham, R., Larson, K.M., Lai, X.A., You, X., Niu, Z., Wu, J., Li, Y. and Liu, J., 2001. Present-day crustal deformation in China constrained by global positioning system measurements. Science, 294(5542), pp.574-577.

Wesnousky, S.G., Kumar, S., Mohindra, R. and Thakur, V.C., 1999. Uplift and convergence along the Himalayan Frontal Thrust of India. Tectonics, 18(6), pp.967-976.

Yin, A., 2006. Cenozoic tectonic evolution of the Himalayan orogen as constrained by along-strike variation of structural geometry, exhumation history, and foreland sedimentation. Earth-Science Reviews, 76(1-2), pp.1-131. 